\title{
Dexamethasone Regimens Alter Spatial Memory and Anxiety Levels in Mice
}

\author{
Olakunle James Onaolapo', Adejoke Yetunde Onaolapo ${ }^{2 *}$, Olufunmi Racheal Akinola², \\ Tolulope Oluwakemi Anisulowo ${ }^{2}$ \\ ${ }^{1}$ Department of Pharmacology, Faculty of Basic Medical Sciences, College of Health Sciences, Ladoke Akintola \\ University of Technology, Oshogbo, Nigeria \\ ${ }^{2}$ Department of Human Anatomy, Faculty of Basic Medical Sciences, College of Health Sciences, Ladoke \\ Akintola University of Technology, Ogbomosho, Nigeria \\ Email: adegbayibiy@yahoo.com, olakunleonaolapo@yahoo.co.uk
}

Received 20 February 2014; revised 22 March 2014; accepted 30 March 2014

Copyright (C) 2014 by authors and Scientific Research Publishing Inc.

This work is licensed under the Creative Commons Attribution International License (CC BY).

http://creativecommons.org/licenses/by/4.0/

(c) (i) Open Access

\begin{abstract}
Acute and sub chronic effects of oral dexamethasone on anxiety and memory in mice were evaluated using the elevated plus maze, Y maze and radial arm maze. Adult male Swiss albino mice assigned to five groups were given vehicle (normal saline), a standard drug (Diazepam or Scopolamine) or one of three selected doses of dexamethasone $(0.5,1.0$ and $1.5 \mathrm{mg} / \mathrm{kg})$ daily for a period of 14 days. Behavioral tests were carried out on days 1 and 14 after administration. Results were analysed using a one-way ANOVA followed by a posthoc test (Student-Newman-Keul) and expressed as mean \pm S.E.M. Elevated plus maze test showed a significant reduction in the time spent in the open arm and in the number of open arm entries compared to control. Results of radial arm and Y maze tasks showed an improvement in spatial memory following dexamethasone administration. Y maze locomotor activity was significantly increased, although radial arm maze exploration did not increase significantly. The study concluded that oral dexamethasone given either acutely or sub chronically has both anxiogenic and memory enhancing effects.
\end{abstract}

\section{Keywords}

Neurobehavior, Dexamethasone, Animal Models, Anxiety

\section{Introduction}

Corticosteroids and a number of their synthetic derivatives have metabolic (glucocorticoid) and electrolyte"Corresponding author. 
regulating (mineralocorticoid) activities; variations, however, occur when comparisons are made between these two activities. These agents find application as replacement therapy while glucocorticoids in particular are used in a variety of inflammatory and autoimmune diseases. Steroid hormones are produced and secreted by the adrenal glands usually in response to stress [1]; the hormones, cortisol and corticosterone (CORT) help to maintain or restore body homeostasis [2] as well as regulate the body's immune response to infections and disease [3].

Glucocorticoids are the final products of the activated hypothalamus-pituitary-adrenal (HPA) axis which is extremely crucial to survival in both man and animals [4] [5]. For more than 60 years, prescription glucocorticoids have been used in the treatment of asthma, allergies, arthritis and dermatological diseases and in the prevention transplant rejection [6].

A variety of systems in the body are sensitive to glucocorticoids largely due to the presence within them of one or more glucocorticoid receptors; amongst them are the peripheral and central nervous system [7], glucocorticoids are lipophilic, and so they are able to cross the blood-brain barrier gaining access to the brain where, by binding to specific receptors (mineralocorticoid (MR) and glucocorticoid (GR) receptors) [8], cause a number of responses. Glucocorticoid receptors are found in large numbers in the hippocampus and are important in memory formation with varying responses documented [4], they have also been shown to affect brain regions that are associated with cognitive and other functions, and this may involve both genomic and non-genomic processes.

Dexamethasone (DEX) is a potent synthetic glucocorticoid with anti-inflammatory and immunosuppressant properties. It is 25 times more potent than cortisol in its glucocorticoid effect; it also has a longer duration of action but little or no mineralocorticoid effect. DEX has a number of systemic side effects such as diabetes, osteoporosis, infection, glaucoma, and cataracts, which are similar to that seen with most glucocorticoids and most of these effects are well documented. Effects of glucocorticoids on the brain were not studied extensively; not until there began to appear in literature reports of severe mood disorders, psychosis and at times suicide or suicidal ideations with glucocorticoid use [9] [10]. A number of animal studies detailing the neurobehavioral, neurochemical and neuro histological effects of naturally occurring glucocorticoids on the different brain regions are however available [11] [12]. Some authors have also studied the effects of dexamethasone in particular on the brain; however, most of the works available have concentrated on the intravenous route of administration [13] [14]. Our aim in this study is to look at certain aspects of the neurobehavioral effects of dexamethasone when the drug is given orally.

\section{Materials and Methods}

\subsection{Reagents and Drugs}

Normal Saline, Diazepam (Valium ${ }^{\circledR}$ ), Scopolamine hydro bromide and Dexamethasone tablets were purchased from the pharmacy, crushed weighed and dissolved in measured volume of isotonic saline solution to get desired concentrations. Dexamethasone at the varying doses $(0.5,1.0$ and $1.5 \mathrm{mg} / \mathrm{kg})$ was administered orally using a cannula.

\subsection{Animals}

A hundred and fifty healthy adult male Swiss albino mice (Empire Breeders, Oshogbo, Osun State, Nigeria) weighing 20 to $25 \mathrm{~g}$ were used. Mice were housed in plastic cages measuring $16 \times 12 \times 10$ inches $(10$ mice in each cage). Housing is a temperature-controlled $\left(22.5^{\circ} \mathrm{C} \pm 2.5^{\circ} \mathrm{C}\right)$ quarters with 12 hours of light. Mice had free access to food and water except during the behavioral tests. The experimental protocol was approved by the University Animal Ethics Committee. All rules applying to animal safety and care were observed.

\subsection{Experimental Method}

This research work was carried out between July and August 2012 in the Histology laboratory of the department of Anatomy, Ladoke Akintola University of Technology, Ogbomosho, Nigeria. Fifty mice were used for each of the experiments. The mice were randomly assigned to five groups of ten animals each. Mice in respective groups received vehicle (normal saline), standard drug (Diazepam at $1 \mathrm{mg} / \mathrm{kg}$ i.p. or Scopolamine at $0.5 \mathrm{mg} / \mathrm{kg}$ i.p.) or one of three doses of dexamethasone $(0.5,1.0$ and $1.5 \mathrm{mg} / \mathrm{kg}$ ) respectively for a period of 14 days. Tests were carried out thirty minutes after the first and last dose of dexamethasone.

The behavioral tests were conducted in a large quiet room between the hours of 8 a.m. and 4 p.m. Effects of 
dexamethasone or vehicle on anxiety behavior were evaluated using the elevated plus maze while its effect on spatial learning and memory were assessed using the Y-maze and radial arm maze. Behaviors were scored by the authors using a stop watch; all mice in one group were tested on the same day. All events were observed manually as previously described [15].

\subsection{Statistical Analysis}

All data were analyzed using one way analysis of variance (ANOVA) followed by post hoc tests (Student Newman Keul's). Results were expressed as Mean \pm S.E.M., $\mathrm{p}<0.05$ was taken as accepted level of significant difference from control.

\section{Results}

\subsection{Effect of Dexamethasone on Percentage Time Spent in Open and Closed Arms}

Figure 1, Figure 2 show the effects of oral dexamethasone on percentage time spent in the closed and open arms following 5 minutes of exposure to the elevated plus maze. On day 1 there was no significant difference in the time spent in either the closed or open arms compared to both control, however on day 14 there was a significant $(\mathrm{F}=$ Closed $\mathrm{arm}=42.68$, Open arm $=39.78, \mathrm{p}<0.05$, degree of freedom $=45)$ increase in time spent in the closed arm and reduction in time spent in the open arm at 0.5 and $1.5 \mathrm{mg} / \mathrm{kg}$ dose compared to control.

\subsection{Effect of Dexamethasone on Number of Open and Closed Arm Entry}

Figure 3, Figure 4 show the effect of oral dexamethasone on number of closed or open arm entries following 5 minutes of exposure to the elevated plus maze. There was no significant difference in number of closed arm entries, either on day 1 or 14 compared control, however there was a significant ( $F=19.16$ (day 1), 9.96 (day 14), $\mathrm{p}<0.05$ ) reduction in number of open arm entries at 0.5 and $1.5 \mathrm{mg} / \mathrm{kg}$ on day 1 and $0.5,1.0 \mathrm{and} 1.5 \mathrm{mg} / \mathrm{kg}$ on day 14 compared to control.

\subsection{Effect of Dexamethasone on Spatial Memory in the Y Maze}

Figure 5 shows the effect of dexamethasone on spatial memory following 5 minutes of exploration in the $\mathrm{Y}$

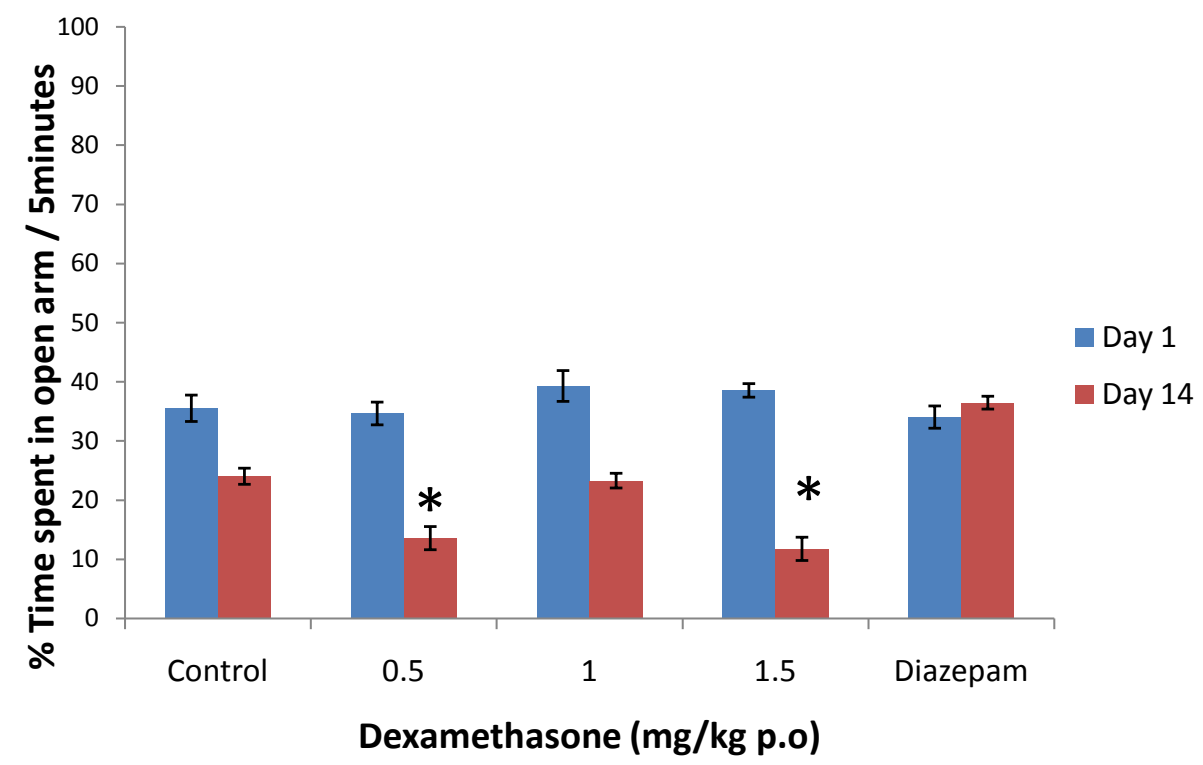

Figure 1. Effect of Dexamethasone $(0.5,1.0$ and $1.5 \mathrm{mg} / \mathrm{kg})$ on percentage time spent in the open arms following 5 minutes of exploration in the elevated plus maze. Each bar represents Mean \pm S.E.M., ${ }^{*} \mathrm{p} \leq 0.05$ compared to the control, $\mathrm{n}=10$. 


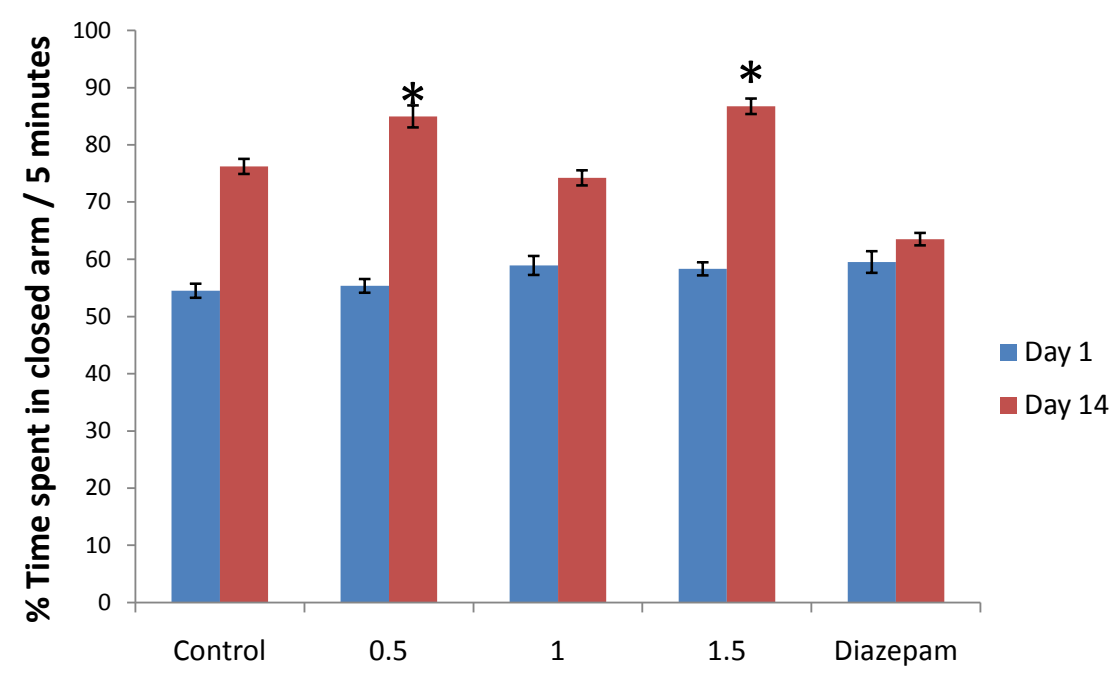

Dexamethasone (mg/kg p.o)

Figure 2. Effect of Dexamethasone $(0.5,1.0$ and $1.5 \mathrm{mg} / \mathrm{kg})$ on percentage time spent in the closed arms following 5 minutes of exploration in the elevated plus maze. Each bar represents Mean \pm S.E.M., ${ }^{*} \mathrm{p} \leq 0.05$ compared to the control, $\mathrm{n}=10$.

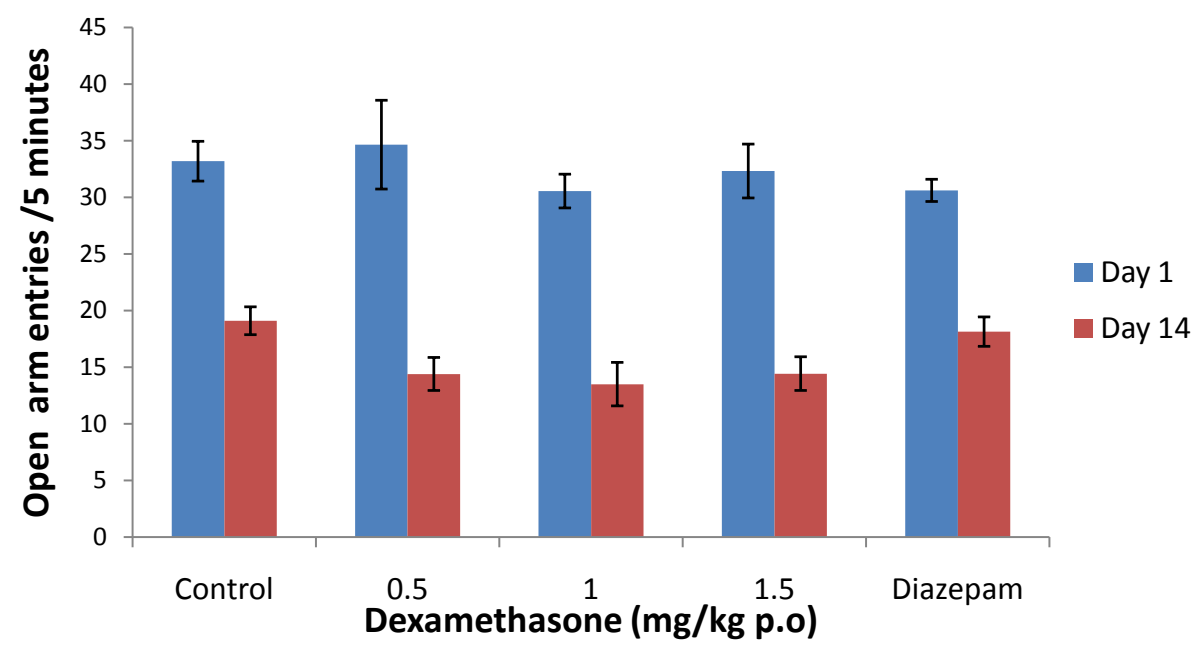

Figure 3. Effect of Dexamethasone (0.5, 1.0 and $1.5 \mathrm{mg} / \mathrm{kg}$ ) number of open arm entry following 5 minutes of exploration in the elevated plus maze. Each bar represents Mean \pm S.E.M., ${ }^{*} \mathrm{p} \leq 0.05$ compared to the control, $\mathrm{n}=10$.

maze. On day 1 there was a significant $(F=52.47, \mathrm{p}<0.05$, degree of freedom $=45)$ increase in spatial memory task performance at 0.5 and $1.5 \mathrm{mg} / \mathrm{kg}$ compared to saline control, on day 14 there was a significant $(\mathrm{F}=91.51$, $\mathrm{p}<0.05$, degree of freedom $=45$ ) increase in spatial memory tasks at all doses compared to scopolamine control whereas compared to saline control there was a significant increase at $0.5 \mathrm{mg} / \mathrm{kg}$ dose and a reduction in memory tasks at 1.0 and $1.5 \mathrm{mg} / \mathrm{kg}$ dose.

\subsection{Effect of Dexamethasone on Y-maze Locomotor Activity}

Figure 6 shows the effect of dexamethasone on locomotor activity following 5 minutes of exploration in the $\mathrm{Y}$ maze. On day 1 there was no significant $(\mathrm{F}=1.21, \mathrm{p}=0.319)$ difference in locomotor activity in all groups that received dexamethasone compared to either saline or scopolamine control, on day 14 however there was a significant $(\mathrm{F}=24.00, \mathrm{p}<0.05)$ increase in locomotor activity in all groups that received dexamethasone compared to control. 


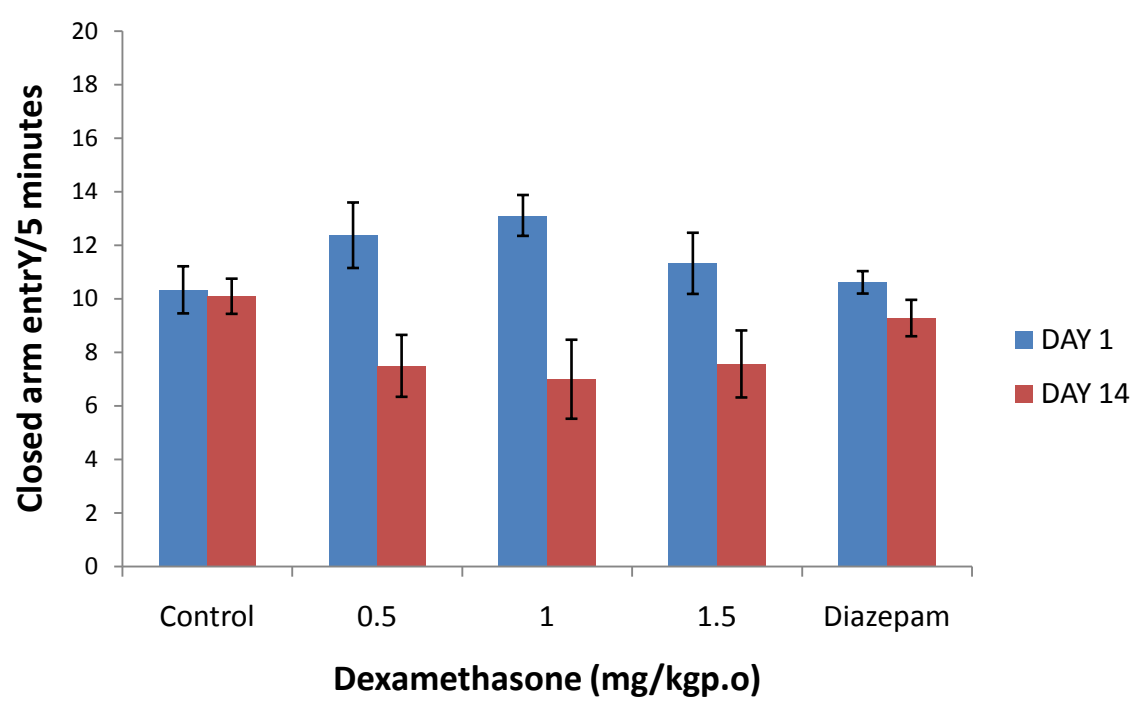

Figure 4. Effect of Dexamethasone (0.5, 1.0 and $1.5 \mathrm{mg} / \mathrm{kg}$ ) number of closed arm entry following 5 minutes of exploration in the elevated plus maze. Each bar represents Mean \pm S.E.M., ${ }^{*} \mathrm{p} \leq 0.05$ compared to the control, $\mathrm{n}=10$.

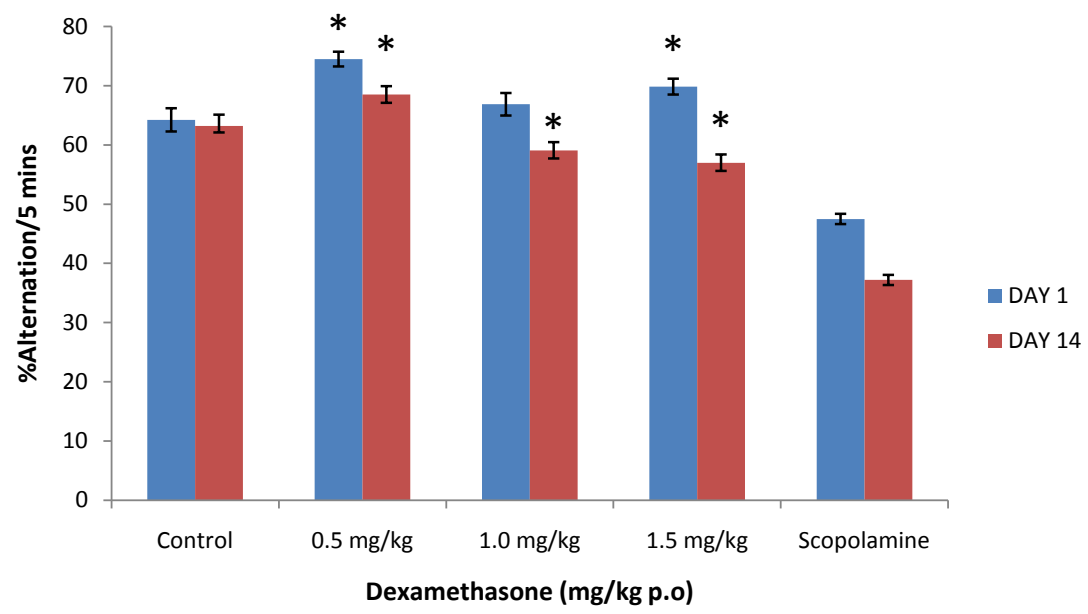

Figure 5. Effect of Dexamethasone $(0.5,1.0$ and $1.5 \mathrm{mg} / \mathrm{kg})$ on spatial memory following 5 minutes of exploration in the $\mathrm{Y}$-maze. Each bar represents Mean \pm S.E.M., * $\mathrm{p} \leq 0.05$ compared to the control, $\mathrm{n}=10$.

\subsection{Effect of Dexamethasone on Percentage Novel Arm Entry in the Radial Arm Maze}

Figure 7 shows the effect of oral dexamethasone on percentage novel arm entry following 5 minutes of exposure to the radial arm maze. There was a significant increase in novel arm entry on days $1(\mathrm{f}=166.3, \mathrm{p}<0.05)$ and $14(\mathrm{f}=380.22, \mathrm{p}<0.05)$ in all groups that received dexamethasone compared to control.

\subsection{Effect of Dexamethasone on Total Arm Entry}

Figure 8 shows the effect of oral dexamethasone on total arm entry following 5 minutes of exposure to the radial arm maze. There was no significant difference in total arm entry on day $1(f=30.13, p=1.000)$ or $14(f=$ $0.51, \mathrm{p}=0.732$ ) in all groups that received dexamethasone compared to control.

\section{Discussion}

Effects of oral dexamethasone on anxiety state and spatial memory in Swiss mice were assessed. Behavioral ef- 


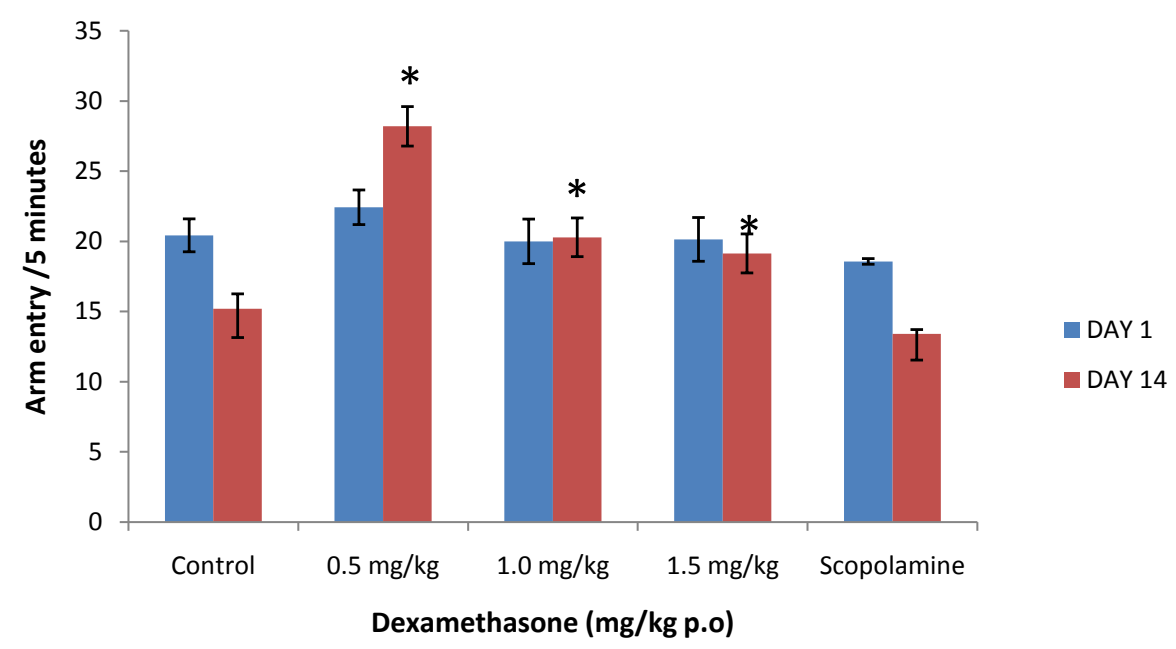

Figure 6. Effect of Dexamethasone $(0.5,1.0$ and $1.5 \mathrm{mg} / \mathrm{kg})$ on locomotor activity following 5 minutes of exploration in the Y-maze. Each bar represents Mean \pm S.E.M., ${ }^{*} \mathrm{p} \leq 0.05$ compared to the control, $\mathrm{n}=10$.

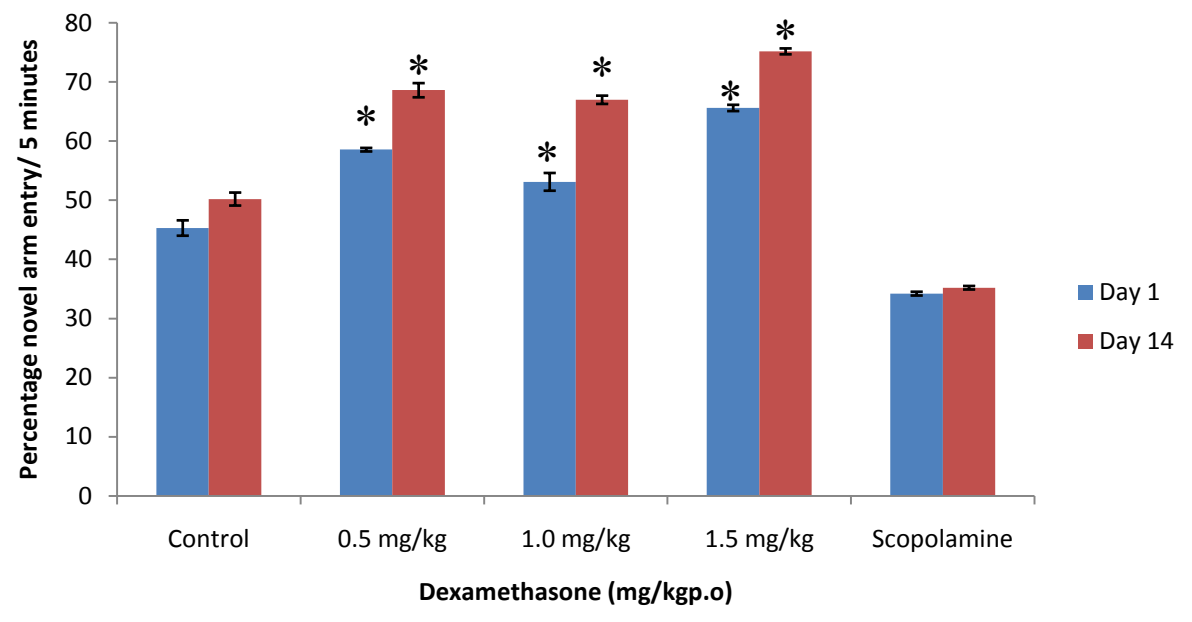

Figure 7. Effect of Dexamethasone (0.5, 1.0 and $1.5 \mathrm{mg} / \mathrm{kg}$ ) on percentage novel arm entry following 5 minutes of exploration in the radial arm maze. Each bar represents Mean \pm S.E.M, ${ }^{*} \mathrm{p} \leq 0.05$ compared to the control, $\mathrm{n}=10$.

fects were examined initially after acute dosing and then after a fourteen day daily dosing regimen using three behavioral models.

The elevated plus maze (EPM) is a model for studying anxiety related behaviors in rodents, it has been widely used in the investigation of the psychological and neurochemical basis of anxiety as well as for screening for anxiety modulating drugs in mouse genotypes [15]-[18]. Elevated plus maze behaviors are based on the natural aversion of rodents for elevated and open space; naturally, rodents avoid open spaces and prefer enclosed spaces, and by extension, the closed arms of the maze are preferred over the open arms. This may however change when the animal is under the influence of drugs with anxiolytic effects such as diazepam which cause a shift in the behavioral response of animals toward exploration of the open arms [15] [19] [20].

From the study, acute administration of dexamethasone did not significantly affect open arm time but resulted in a significant reduction in number of open arm entries however, after14 days there was a significant reduction in time spent in open arm and number of open arm entries. Reduction in time spent and distance travelled in the open arms of the EPM are typically thought to reflect an anxiogenic like phenotype. In a recent study, acute intravenous administration of dexamethasone at 0.5 and $1 \mathrm{mg} / \mathrm{kg}$ caused anxiolysis in mice [13]. This contrasts the results of our study where anxiety related behavior following oral dexamethasone did not differ significantly 


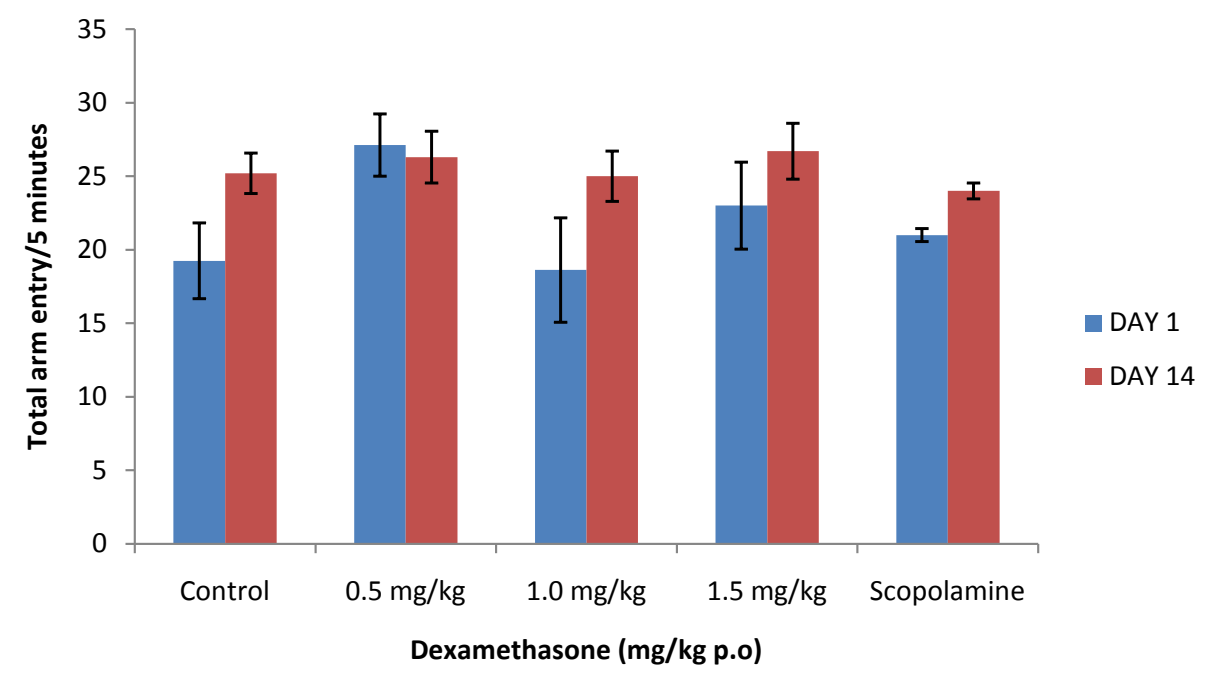

Figure 8. Effect of Dexamethasone (0.5, 1.0 and $1.5 \mathrm{mg} / \mathrm{kg}$ ) on total arm entry following 5 minutes of exploration in the radial arm maze. Each bar represents Mean \pm S.E.M., ${ }^{*} \mathrm{p} \leq 0.05$ compared to the control, $\mathrm{n}=10$.

from control acutely but sub chronically was anxiogenic. While open arm time (following acute administration) increased at 1 and $1.5 \mathrm{mg} / \mathrm{kg}$ in comparison to controls, increments were only marginal and therefore not big enough to suggest an anxiolytic effect at these doses.

Studies on the effect of prenatal and postnatal treatment with dexamethasone on anxiety level in adults have shown that DEX in utero increases anxiety like behaviors in adult subjects years after administration; most of these studies however have used the intravenous routes of administration [13]. The stress or fear inducing effects of DEX may be attributable to its effects on the fore brain glucocorticoid receptor signalling system that encompass the cerebral cortex, hippocampus, nucleus accumbens, caudate-putamen and basolateral/basomedial amygdala, leading to alterations in behavioral and physiological reactivity to stress.

Glutamate and GABA (gamma amino butyric acid) are the predominant neurotransmitters in the central nervous system and together they account for about $90 \%$ of neurotransmission. Glutamate GABA imbalance has been implicated in anxiety disorders and the response seen here could be the result of dexamethasone eliciting an increase in brain glutamate levels enough to alter the glutamate GABA balance. Increases in glutamate efflux in brain regions such as the prefrontal cortex and hippocampus was observed after stress; also a lack of GAD65 enzyme which is responsible for converting glutamate into GABA leads to exhibition of anxiety in mice [21] [22]. Actions of corticosteroids in the limbic region of the brain are strongly linked to their observed anxiogenic response and a disruption of their forebrain/limbic circuits is probably involved in the development of affective and anxiety disorders [23]. Dexamethasone administered to rats has been shown to increase the release of glutamate in the region of the limbic cortex in a dose dependent manner [24].

Anxiogenic effects of dexamethasone observed here is believed to have resulted from the ability of DEX to alter the glutamate GABA balance by enhancing glutamate release in brain regions that are critical for anxiogenic response even when the drug is given through the oral route. A sustained anxiogenic response over the period of study as observed here suggests that repeated oral administration of DEX has the capability to continue to alter glutamate GABA balance and elicit an anxiogenic response.

The Y-maze is a behavioral model that can be used to investigate locomotor activity as well as learning and memory; it assesses hippocampus dependent navigational behaviors of rodents [25]. The radial arm maze is an appetitive motivated task useful in assessing spatial reference as well as spatial working memory performance and factors affecting these processes [26]. The results of both the Y maze and radial arm maze studies showed an increase in spatial memory scores in both groups that received DEX compared to controls. Acute and chronic actions of glucocorticoids on memory processes have been documented to differ in many respects; this includes differences in behavioral outcomes as well as in the cellular and molecular mechanisms involved [4] [27]. An important feature of the acute effects of glucocorticoids on memory function is the ability to induce both facilitating and impairing effects on memory [7]. In this study, acute administration of dexamethasone resulted in im- 
provement in memory in both the radial arm and Y maze; this has been attributed to the ability of glucocorticoids to induce the AMPA type glutamate receptors in the hippocampus. Increased hippocampal AMPAR trafficking has recently been implicated in the facilitating action of corticosterone during spatial learning in mice [7]; since dexamethasone acts on the same receptors as the naturally occurring glucocorticoids, similar effects are expected with DEX administration. Significant improvements in spatial memory were recorded when mice were tested again after 14 days of administration.

The results of Y maze locomotor activity showed a significant increase both acutely and after 14 days of administration of dexamethasone compared to control; increase in locomotor activity in rodents has been thought to reflect dopamine release in the striatum [28] [29], radial arm maze locomotor activity increase were however not statistically significant.

\section{Conclusion}

The study demonstrates the ability of oral dexamethasone regimens to alter anxiety states and memory in Swiss mice, thus establishing that behavioral effects ascribed to DEX given by other routes can also be seen when it is given orally.

\section{References}

[1] McEwen, B.S. (1999) Stress and Hippocampal Plasticity. Annual Review of Neuroscience, 22, 105-122. http://dx.doi.org/10.1146/annurev.neuro.22.1.105

[2] Chrousos, G.P. and Gold, P.W. (1992) The Concepts of Stress and Stress System Disorders: Overview of Physical and Behavioral Homeostasis. Journal of the American Medical Association, 267, 1244-1252. http://dx.doi.org/10.1001/jama.1992.03480090092034

[3] Ruzek, M.C., Pearce, B.D., Miller, A.H. and Biron, C.A. (1999) Endogenous Glucocorticoids Protect against Cytokine-Mediated Lethality during Viral Infection. Journal of Immunology, 162, 3527-3533.

[4] Sandi, C.C. (2004) Stress, Cognitive Impairment and Cell Adhesion Molecules. Nature Reviews Neuroscience, 5, 917930. http://dx.doi.org/10.1038/nrn1555

[5] Fardet, L., Kassar, A. and Cabane, J. (2007) Corticosteroid-Induced Adverse Events in Adults: Frequency, Screening and Prevention. Drug Safety, 30, 861-881. http://dx.doi.org/10.2165/00002018-200730100-00005

[6] Herman, J.P. and Cullinan, W.E. (1997) Neurocircuitry of Stress: Central Control of the Hypothalamo-Pituitary-Adrenocortical Axis. Trends in Neuroscience, 20, 78-84. http://dx.doi.org/10.1016/S0166-2236(96)10069-2

[7] Sandi, C. and Pinelo-Nava, M.T. (2007) Stress and Memory: Behavioral Effects and Neurobiological Mechanisms. Neural Plasticity, 2007, 78970.

[8] Rees, L. (1953) Psychological Concomitants of Cortisone and ACTH Therapy. Journal of Mental Science, 99, 497504.

[9] Rome, H.P. and Braceland, F.J. (1952) The Psychological Response to ACTH, Cortisone, Hydrocortisone, and Related Steroid Substances. American Journal of Psychiatry, 108, 641-651.

[10] Rubinow, D.R., Post, R.M., Savard, R. and Gold, P.W. (1984) Cortisol Hypersecretion and Cognitive Impairment in Depression. Archives of General Psychiatry, 41, 279-283. http://dx.doi.org/10.1001/archpsyc.1984.01790140069008

[11] McLay, R.N., Freeman, S.M. and Zadina, J.E. (1998) Chronic Corticosterone Impairs Memory Performance in the Barnes Maze. Physiology and Behavior, 63, 933-937. http://dx.doi.org/10.1016/S0031-9384(97)00529-5

[12] Rayburn, W.F., Christensen, H.D. and Gonzalez, C.L. (1997) A Placebo-Controlled Comparison between Betamethasone and Dexamethasone for Fetal Maturation: Differences in Neurobehavioral Development of Mice Offspring. American Journal of Obstetrics \& Gynecology, 176, 842-851. http://dx.doi.org/10.1016/S0002-9378(97)70609-4

[13] Vafaei, A.A., Rashidy-Pour, A. and Taherian, A.A. (2008) Peripheral Injection of Dexamethasone Modulates Anxiety Related Behaviors. In: Mice: An Interaction with Opioidergic Neurons. Pakistan Journal of Pharmaceutical Sciences, 21, 285-289.

[14] Onaolapo, O.J., Onaolapo, A.Y., Mosaku, T.J., Onigbinde, O.A. and Oyedele, R.A. (2012) Elevated Plus Maze and Y-Maze Behavioral Effects of Subchronic, Oral Low Dose Monosodium Glutamate in Swiss Albino Mice. IOSR Journal of Pharmacy and Biological Sciences, 3, 21-27. http://dx.doi.org/10.9790/3008-0342127

[15] Onaolapo, O.J., Onaolapo, A.Y., Awe, E.O., Jibunor, N. and Oyeleke, B. (2013) Oral Artesunate-Amodiaquine Combination Causes Anxiolysis and Impaired Cognition in Healthy Swiss Mice. IOSR Journal of Pharmacy and Biological Sciences, 7, 97-102. http://dx.doi.org/10.9790/3008-07297102 
[16] Bourin, M. (1997) Animal Models of Anxiety: Are They Suitable for Predicting Drug Action in Humans? Polish Journal of Pharmacology, 49, 79-84.

[17] File, S.E. (2001) Factors Controlling Measures of Anxiety and Responses to Novelty in the Mouse. Behavioural Brain Research, 125, 151-157. http://dx.doi.org/10.1016/S0166-4328(01)00292-3

[18] Belzung, C. and Griebel, G. (2001) Measuring Normal and Pathological Anxiety-Like Behaviour in Mice: A Review. Behavioural Brain Research, 125, 141-149. http://dx.doi.org/10.1016/S0166-4328(01)00291-1

[19] Handley, S.L. and Mithani, S. (1984) Effects of Adrenoreceptor Agonists and Antagonists in a Maze-Exploration Model of Fear-Motivated Behaviour. Naunyn-Schmiedeberg's Archives of Pharmacology, 327, 1-5.

[20] Montgomery, K.C. (1958) The Relation between Fear Induced by Novel Stimulation and Exploratory Behavior. Journal of Comparative and Physiological Psychology, 48, 254-260. http://dx.doi.org/10.1037/h0043788

[21] Derbenev, A.V. and Smith, B.N. (2013) Dexamethasone Rapidly Increases GABA Release in the Dorsal Motor Nucleus of the Vagus via Retrograde Messenger-Mediated Enhancement of TRPV1 Activity. PLoS ONE, 8, e70505. http://dx.doi.org/10.1371/journal.pone.0070505

[22] Wierońska, J.M., Stachowicz, K., Pałucha-Poniewiera, A., Acher, F., Brański, P. and Pilc, A. (2010) Metabotropic Glutamate Receptor 4 Novel Agonist LSP1-2111 with Anxiolytic, but Not Antidepressant-Like Activity, Mediated by Serotonergic and GABAergic Systems. Neuropharmacology, 59, 627-634. http://dx.doi.org/10.1016/j.neuropharm.2010.08.008

[23] Boyle, M.P., Benedict, J.K., Vogt, K., Wozniak, D.F. and Muglia, L.J. (2006) Forebrain Glucocorticoid Receptors Modulate Anxiety-Associated Locomotor Activation and Adrenal Responsiveness. The Journal of Neuroscience, 26, 1971-1978. http://dx.doi.org/10.1523/JNEUROSCI.2173-05.2006

[24] Zhang, X., Kan, Q., Fu, Y., Liu, S., Dai, Z. and Dong, Y. (2012) Noradrenergic Activity Regulated DexamethasoneInduced Increase of 5- $\mathrm{HT}_{3}$ Receptor-Mediated Glutamate Release in the Rat's Prelimbic Cortex. Biochimica et Biophysica Acta (BBA)-Molecular Cell Research, 1823, 2157-2167.

[25] Conrad, C.D. (2005) The Relationship between Acute Glucocorticoid Levels and Hippocampal Function Depends upon Task Aversiveness and Memory Processing State. Nonlinearity in Biology, Toxicology, and Medicine, 3, 57-78.

[26] Kulkarni, S.K. (2005) Handbook of Experimental Pharmacology. 3rd Edition, Springer, Berlin, 56-66.

[27] Sandi, C. (2011) Glucocorticoids Act on Glutamatergic Pathways to Affect Memory Processes. Trends in Neurosciences, 34. http://dx.doi.org/10.1016/j.tins.2011.01.006

[28] Murph, N.P., Lam, H.A. and Maidment, N.T. (2001) A Comparison of Morphine-Induced Locomotor Activity and Mesolimbic Dopamine Release in C57BL6, 129Sv and DBA2 Mice. Journal of Neurochemistry, 79, 626-635. http://dx.doi.org/10.1046/j.1471-4159.2001.00599.x

[29] Porras, G., DeDeurwaerdere, P., Moison, D. and Spampinato, U. (2003) Conditional Involvement of Striatal Serotonin3 Receptors in the Control of in Vivo Dopamine Outflow in the Rat Striatum. The European Journal of Neuroscience, 17, 771-781. http://dx.doi.org/10.1046/j.1460-9568.2003.02512.x 